\title{
Acknowledgement of Financial Support
}

During 2013, ORCA has continued to receive generous financial support from both charitable bodies and commercial organisations. This has enabled ORCA to carry out its work in education and in the stimulation of caries research internationally.

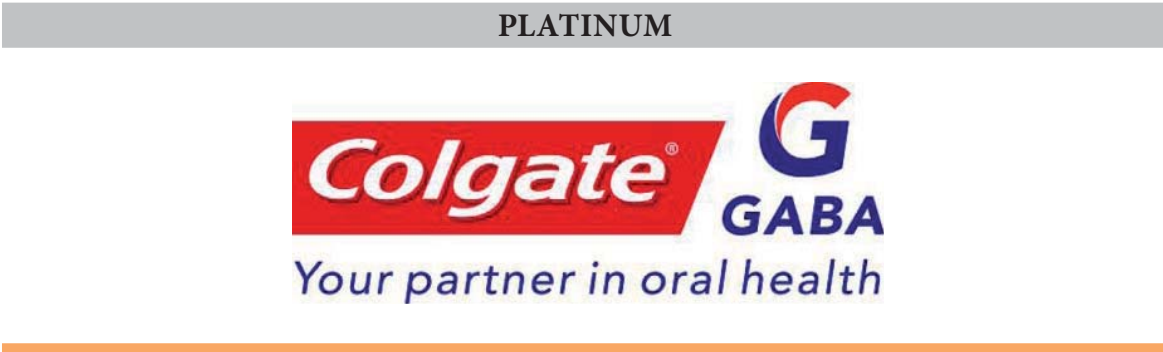

GOLD

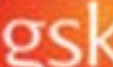

GlaxoSmithKline

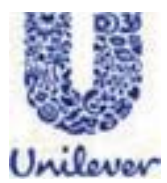

\section{BASIC}

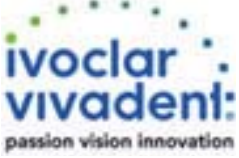

- osugar Nutrition UK
Iife. Iove.

LON"

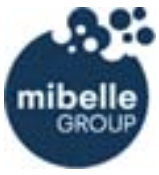

(E)

ROQUETTE

KaVo. Dental Excellence. 